\title{
Perfil educacional da população não alfabetizada no Rio Grande do Norte no ano de
}

\section{0}

\author{
Educational profile of the illiterate population in Rio Grande do Norte in 2010 \\ Perfil educativo de la población analfabeta de Rio Grande do Norte en 2010
}

\author{
Adriano Menino de Macêdo Júnior \\ ORCID: https://orcid.org/0000-0001-6367-1088 \\ Universidade Estadual do Rio Grande do Norte, Brasil \\ E-mail: adrianomenino2016@gmail.com \\ Swianny Rodrigues de Oliveira \\ ORCID: https://orcid.org/0000-0002-5297-139X \\ Universidade Federal do Rio Grande do Norte, Brasil \\ E-mail: rswianny@gmail.com \\ Clécio Danilo Dias da Silva \\ ORCID: https://orcid.org/0000-0002-7776-8830 \\ Universidade Federal do Rio Grande do Norte, Brasil \\ E-mail: danilodiass18@gmail.com \\ Eliana Aquino dos Santos \\ ORCID: https://orcid.org/0000-0002-7780-4096 \\ Universidade Federal do Rio Grande do Norte, Brasil \\ E-mail: eliana.aquino2012@gmail.com \\ Jhuliete Duarte da Silva \\ ORCID: https://orcid.org/0000-0002-5957-2519 \\ Faculdade Venda Nova do Imigrante, Brasil \\ E-mail: drajhuliete@gmail.com \\ Mariana César dos Santos \\ ORCID: https://orcid.org/0000-0003-2782-1776 \\ Universidade Federal do Rio Grande do Norte, Brasil \\ E-mail: marianacesar20@yahoo.com.br
}

\begin{abstract}
Resumo
O presente artigo enfatiza a problemática do analfabetismo no Estado do Rio Grande do Norte - RN, evidenciando variáveis da população em seu contexto social. Inúmeros são os fatores que contribuem para a evasão escolar, a falta de novas metodologias de ensino, bem como uma atenção especifica para cada tipo social de aluno tem aumentado às taxas de analfabetismo nos últimos anos. O objetivo deste trabalho é expor muitos dos fatores que ocasionam a evasão do aluno da escola, em suas muitas variáveis aqui expostas, o analfabetismo é um problema mundial, e deve ser combatido com a elaboração de muitos projetos de educação e tentar estender a educação por todo território nacional, o presente trabalho também colabora para que autoridades públicas tenha consciência do tão grave é a temática aqui envolvida, o analfabetismo no Brasil. Está pesquisa foi desenvolvida na forma descritiva e retrospectiva do ano de 2010, com dados fornecidos e extraídos da base de dados DATASUS. As variáveis avaliadas na discussão foram: taxa de pessoas não alfabetizadas, coletada no ano de 2010, munícipios com taxas de pessoas não alfabetizadas registradas, faixa etária das pessoas não alfabetizadas que residem nos munícipios registrados e a zona de residência dessas pessoas não alfabetizadas. Os fatores econômicos, políticos e sociais são decisivos na vida da população, pois eles vão decidir quem terá oferta e acesso a educação, essa dinâmica que sempre apresenta desigualdade na distribuição de recursos financeiros tem colocado a educação dos brasileiros em xeque.
\end{abstract}

Palavras-chave: Analfabetismo; Educação; População; Ensino.

\begin{abstract}
This article emphasizes the problem of illiteracy in the State of Rio Grande do Norte - RN, highlighting population variables in their social context. Countless factors are contributing to school dropout, the lack of new teaching methodologies, as well as specific attention to each social type of student has increased illiteracy rates in recent years. The objective of this work is to expose many of the factors that cause the evasion of the student from the school, in its many variables exposed here, illiteracy is a worldwide problem, and must be combated with the elaboration of many education projects and try to extend education by all over the national territory, the present work also helps public authorities to be aware of how serious the issue involved here is, illiteracy in Brazil. This research was developed in a descriptive and retrospective way from the year 2010, with data provided and extracted from the DATASUS database. The variables assessed in the discussion were: rate of illiterate people, collected in 2010, municipalities with registered illiterate person rates, age group of illiterate people living in registered municipalities and the area of
\end{abstract}


residence of these illiterate people. Economic, political and social factors are decisive in the life of the population, as they will decide who will have access to and access to education, this dynamic that always presents inequality in the distribution of financial resources has put the education of Brazilians in check.

Keywords: Illiteracy; Education; Population; Teaching.

\section{Resumen}

Este artículo enfatiza el problema del analfabetismo en el Estado de Rio Grande do Norte - RN, destacando las variables poblacionales en su contexto social. Innumerables factores están contribuyendo a la deserción escolar, la falta de nuevas metodologías de enseñanza, así como la atención específica a cada tipo social de estudiante ha aumentado las tasas de analfabetismo en los últimos años. El objetivo de este trabajo es exponer muchos de los factores que provocan la evasión del alumno de la escuela, en sus múltiples variables aquí expuestas, el analfabetismo es un problema mundial, y hay que combatirlo con la elaboración de muchos proyectos educativos y tratar de extender la educación por todo el territorio nacional, el presente trabajo también contribuye para que las autoridades públicas sean conscientes de la gravedad del tema que se trata aquí, el analfabetismo en Brasil. Esta investigación se realizó de forma descriptiva y retrospectiva para el año 2010, con datos aportados y extraídos de la base de datos DATASUS. Las variables evaluadas en la discusión fueron: tasa de analfabetos, recolectada en 2010, municipios con tasa de analfabetos registrados, grupo de edad de analfabetos residentes en municipios registrados y zona de residencia de estos analfabetos. Los factores económicos, políticos y sociales son determinantes en la vida de la población, ya que ellos decidirán quién tendrá acceso y acceso a la educación, esta dinámica que siempre presenta desigualdad en la distribución de los recursos financieros ha puesto en jaque la educación de los brasileños.

Palabras clave: Analfabetismo; Educación; Población; Enseñando.

\section{Introdução}

Segundo dados do Instituto Brasileiro de Geografia e Estatística (IBGE) o Brasil possuía faixa etária de pessoas acimas dos 15 anos de idade que não sabem ler nem escrever, estimasse que 8\% ( $\mathrm{n}=12,9$ milhões de pessoas) da população Brasileira sejam analfabetas, esse valores alteram de acordo com cada região do país, a Região Nordeste apresenta percentual de $16,2 \%, 4 \%$ na Região sul e Sudeste, pesquisas apontam que o fator da idade influencia muito, no Brasil temos uma taxa de $0,8 \%$ de analfabetismo entre jovens de 15 a 19 anos e de 22,3\% em adultos com mais de 60 anos. A etnia de cada população pode influenciar também, a população negra corresponde a 11,2\% de analfabetismo no Brasil, percentual bem superior quando comparados aos brancos que apresentam 5\% da população não alfabetizada do Brasil (Braga, Mazzeu, 2017; IBGE, 2015).

Estudos recentes divulgados apontam que a falta de estímulos, voltado a certas disciplinas, aulas de disciplinas como: matemática, biologia, artes, etc. que deveriam ser voltadas em sua maior parte praticas, na verdade são mais teóricas. Muitas das vezes o professor está apenas munido do quadro negro e giz, isso ocasiona desinteresse direto, nos alunos, principalmente os de ensino fundamental e médio. Sem novas técnicas implantadas na metodologia de ensino, a transferência do saber é dificultada. Os professores docentes têm encontrado cada vez mais desafios, uma vez que faltam recursos para aplicar aulas praticas e materiais didáticos adequados (Souza et al., 2017).

[...] é possível a utilização de vários materiais que auxiliem a desenvolver o processo de ensino e de aprendizagem, isso faz com que facilite a relação professor - aluno - conhecimento (Souza, 2007, p. 110).

[...] o quadro negro, um recurso inestimável, é cada vez menos e mais ineptamente usado, pois professores em algumas aulas, colocam no quadro os esquemas, ou textos que serão trabalhados antes de exporem o conteúdo aos alunos. Dessa forma, os mesmos copiam o que está no quadro e não acompanham o assunto a ser abordado. Portanto o ideal é que o professor utilize e faça seus esquemas conforme exponha o conteúdo para que os alunos consigam acompanhar o raciocínio que será desenvolvido (Krasilchik, 2008, p. 63).

É partindo dessa premissa que muitos dos alunos são desencorajados com o tempo a gostar de estudar, pois o professor encontra muitas dificuldades em trazer o novo e diferente para as salas de aulas. Sem atratividade e motivação, esse aluno encontra dificuldade para construir sua própria linha de raciocínio e conhecimento voltado às disciplinas, é importante que a instituição de ensino motive e se atualize em diversas maneiras de aprendizados. Muitos alunos abandonam a escola por falta de estímulos, fazendo com que esse jovem entre em uma vida desertora. (Nicola, Paniz, 2017). 
[...] Não resta dúvida que os recursos didáticos desempenham grande importância na aprendizagem. Para esse processo, o professor deve apostar e acreditar na capacidade do aluno de construir seu próprio conhecimento, incentivando-o e criando situações que o leve a refletir e a estabelecer relação entre diversos contextos do dia a dia, produzindo assim, novos conhecimentos, conscientizando ainda o aluno, de que o conhecimento não é dado como algo terminado e acabado, mas sim que ele está continuamente em construção através das interações dos indivíduos com o meio físico e social. (Becker, 1992 apud Silva et al. 2012, p. 2).

[...] os recursos didáticos são componentes do ambiente educacional que estimulam os educandos, facilitando e enriquecendo o processo de ensino e aprendizagem [...] Os recursos didático-pedagógicos são componentes do ambiente educacional estimuladores do educando, facilitando e enriquecendo o processo de ensino e aprendizagem. Dessa forma, tudo o que se encontra no ambiente onde ocorre o processo ensino-aprendizagem pode se transformar em um ótimo recurso didático, desde que utilizado de forma adequada (Santos, Belmino, 2013, p. 1; 3).

A falta de compreensão do professor frente ao desenvolvimento e adoção de novas metodologias, vindas das novas tecnologias, não permite diversificar a criatividade dos assuntos explanados em sala de aula, portanto, o professor é a ponte para o desenvolvimento consciente e reflexivo do conhecimento, introduzindo pedagogicamente esses recursos modificando as perspectivas do ensino escolar. O professor é o transmissor do conhecimento, os jovens depositam a sua confiança nele, a falta de empatia e amor do profissional desencadeiam o abandono dos alunos da instituição de ensino. (Santos, Souza, 2019).

O objetivo deste trabalho é expor muitos dos fatores que ocasionam a evasão do aluno da escola, em suas muitas variáveis aqui expostas, o analfabetismo é um problema mundial, e deve ser combatido com a elaboração de muitos projetos de educação e tentar estender a educação por todo território nacional, o presente trabalho também colabora para que autoridades públicas tenha consciência do tão grave é a temática aqui envolvida, o analfabetismo no Brasil.

\section{Metodologia}

Considerando os objetivos propostos e métodos empregados, a presente pesquisa se caracteriza como qualitativa com procedimentos direcionados à pesquisa bibliográfica. De acordo com Oliveira (2016) a pesquisa qualitativa busca explicar o significado e as características das informações do objeto de estudo em seu contexto histórico (ou estrutural) em uma perspectiva mais profunda. Ela não se empenha em mensurar o comportamento dos investigados quantitativamente.

Nesse contexto, Flick (2009) destaca que os pesquisadores que utilizam métodos qualitativos visam "explicar o porquê das coisas, exprimindo o que convém ser feito, mas não quantificam os valores e as trocas simbólicas nem se submetem à prova de fatos, pois os dados analisados são não-métricos (suscitados e de interação) e se valem de diferentes abordagens. No que diz respeito à Pesquisa bibliográfica, Prodanov e Freitas (2013) afirmam que ela é efetivada a partir de materiais já publicados, como por exemplo: livros, revistas, publicações em periódicos e artigos científicos, jornais, boletins, monografias, dissertações, teses, material cartográfico, internet. Ainda de acordo com os autores, ela tem com objetivo "colocar o pesquisador em contato direto com todo material já escrito sobre o assunto da pesquisa" (Prodanov, Freitas, 2013).

Os dados foram extraídos da base de dados DATASUS, onde foram filtrados na plataforma informações referente ao ano de 2010, visto que, na última atualização sobre o número de pessoas não alfabetizadas foi registrada na Região Nordeste, estado do Rio Grande do Norte (RN), Brasil, foram investigados 167 munícipios do RN, nos quais apenas 11 munícipios apresentaram pessoas não alfabetizadas. As buscas também foram realizadas nas bases de dados Scientific Eletronic Library Online - SciELO, Google Acadêmico, Pubmed, assim como em repositórios de universidades públicas e privadas, empregando-se as palavras chave: analfabetismo, educação, população.

As variáveis avaliadas na discussão foram: taxa de pessoas não alfabetizadas, coletada no ano de 2010, munícipios com taxas de pessoas não alfabetizadas registradas, faixa etária das pessoas não alfabetizadas que residem nos munícipios registrados e a zona de residência dessas pessoas não alfabetizadas.

Todos os dados coletados para análise foram selecionados e obtidos por meio do aplicativo TABNET, a partir de suas 
caixas de opções (linha, coluna e conteúdo). Por se tratar de dados secundários de um banco de domínio público, não foi necessário submeter o trabalho ao Comitê de Ética em Pesquisa em Seres Humanos (CEP).

\section{Resultados e Discussão}

O processo de alfabetização é de suma importância para toda a população brasileira, ela desempenha um papel fundamental na vida estudantil de quem passa por ela, e uma vez que o processo de educação tornasse ineficaz, pode trazer sequelas que prejudicam o desempenho do estudante nas próximas series e no decorrer da vida (Lima Winchuar, Aguera, 2018). O RN registrou 111.668 mil casos de pessoas não alfabetizadas, no ano de 2010, dos 167 munícipios analisados apenas $0,14 \%$ ( $n=11$ munícipios), identificaram pessoas em condições de não alfabetização.

No Gráfico 1, podemos verificar os munícipios que notificaram pessoas não alfabetizadas em 2010, o maior número de pessoas não alfabetizadas foi no munícipio de Nata - RN, com percentual de 44,2\% ( $\mathrm{n}=49.386$ ), o munícipio com menos taxa foi o de Maxaranguape $-\mathrm{RN}$, com 1,2\% ( $\mathrm{n}=1.438)$.

Gráfico 1. População não alfabetizada segundo o munícipio.

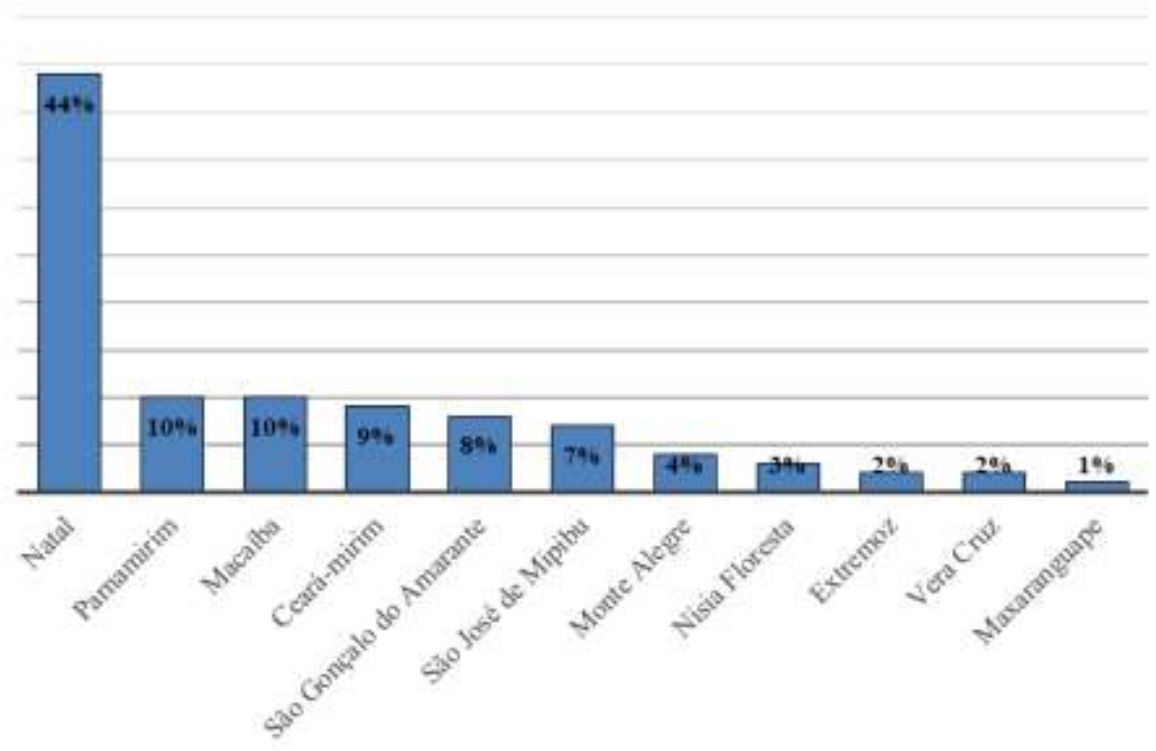

Fonte: DATASUS (2021).

Não é possível trabalhar a educação no contexto social isolado de como ocorre na sociedade, à educação não é um processo individual, e sim um processo social, existe uma serie de fatores que influenciam a adesão da criança na escola, a família é um dos principais motivos, uma vez que a família não participa da vida educativa do jovem, a sobrecarga do educador aumenta, podendo comprometer a alfabetização (Medeiros, 2018).

Pessoas alegam abandonar os estudos ou até mesmo nem inicia-los, por falta de oportunidades, acesso limitado ao sistema educacional é um problema em todo o Brasil, os motivos também estão relacionados a problemas familiares (Oliveira Pinto, 2018). A falta de recursos financeiros destas famílias também obrigam os membros desta, procurar trabalho, a zona rural é a que tem mais dificuldade em manter os jovens na escola, pois faltam transportes públicos em determinadas áreas, falta de escolas, isso contribui para o abandono dos estudos (Boas et al., 2019).

No Gráfico 2, verificamos o total da população não alfabetizada segunda a variável Sexo, onde destacamos que da população masculina não alfabetizada chega no total de $51,5 \%$ do total e mulheres com $48,4 \%$ do total não alfabetizado. 
Gráfico 2. População não alfabetizada segundo o sexo.

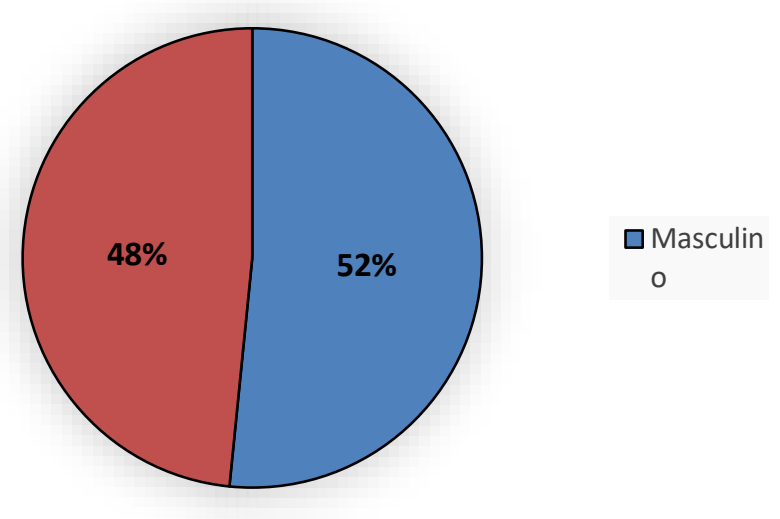

Fonte: DATASUS (2021).

Nesse ponto de vista podemos alegar os seguintes fatores para essa evasão escolar, as condições desfavoráveis financeiras, obrigando esses jovens a se tornar mais um contribuinte para pagar despesas na residência. Com relação ás mulheres podemos destacar a maternidade precoce, adolescentes se sente diversas vezes constrangida pela sociedade, que há recrimina, e também tempo indisponível para conciliar a criação do filho com os estudos. (Soares, Ferro, 2019).

O Nordeste brasileiro tem a maior taxa de analfabetismo do País, com um contingente de quase oito milhões de analfabetos, o que corresponde a 50\% do total do País, atingindo diversas faixas etárias. (Soares e Ferro, 2019). No Gráfico 3 , classificamos a taxa de analfabetismo segundo a variável de da faixa etária, onde a maior faixa etária não alfabetizada é a de 40 a 59 anos, com percentual de $35,7 \%$ do total investigado.

Gráfico 3. População não alfabetizada segundo a faixa etária.

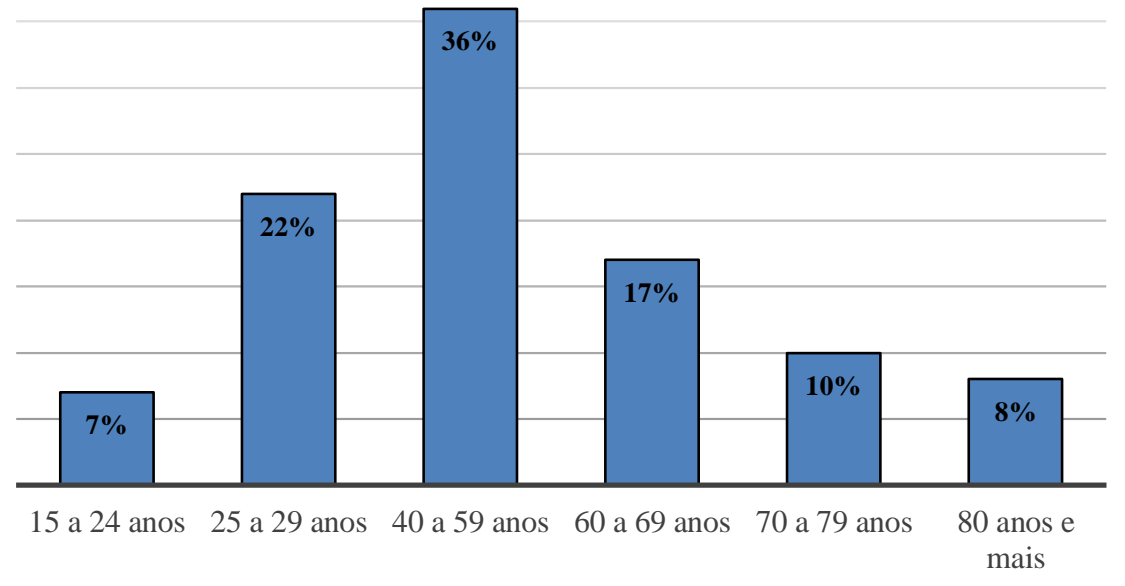

Fonte: DATASUS (2021).

Cada faixa etária tem sua particularidade e expectativa diferente, os fatores podem variar bastante, a baixa qualidade das escolas em abrigar os estudantes, causam desinteresse dos mesmos, fatores como o envolvimento com atividades ilícitas de jovens, como as drogas, causa o afastamento desses alunos das escolas (Barbalho, 2019).

Consoante Fonseca e Negri (2019) destacam em seu trabalho que, a Educação de Jovens e Adultos (EJA) no Brasil, sofre constante preconceito, pois, esta vista a uma má fama de Ensino Noturno de baixa qualidade, que somente recebe em 
estudantes, de idade avançada que não tiveram oportunidade em concluir seus estudos no prazo estipulado, isso é um fator determinante para a falta de estimulo para que as pessoas não concluam seus estudos.

Outro fator que deve ser levado em consideração para a falta do estimulo do aluno optante do EJA, é a metodologia e didática ofertados pelos profissionais de ensino, muitas vezes os alunos com idade superior não se sentem a vontade com métodos utilizados em adolescentes, o professor deve atualizar suas didáticas, adotando para o EJA, o ensino por investigação, aguçando o saber desse aluno, para que o mesmo não se sinta posto em uma situação diferente. (Scarpa, Campos 2018).

$\mathrm{Na}$ Gráfico 4, evidencia a situação de localidade da população não alfabetizada, onde na zona urbana o percentual alcançou $74,7 \%$ do total de casos, e na zona rural alcançou a taxa de $25,2 \%$ de pessoas não alfabetizadas.

Gráfico 4. População não alfabetizada segundo a Zona urbana e rural.

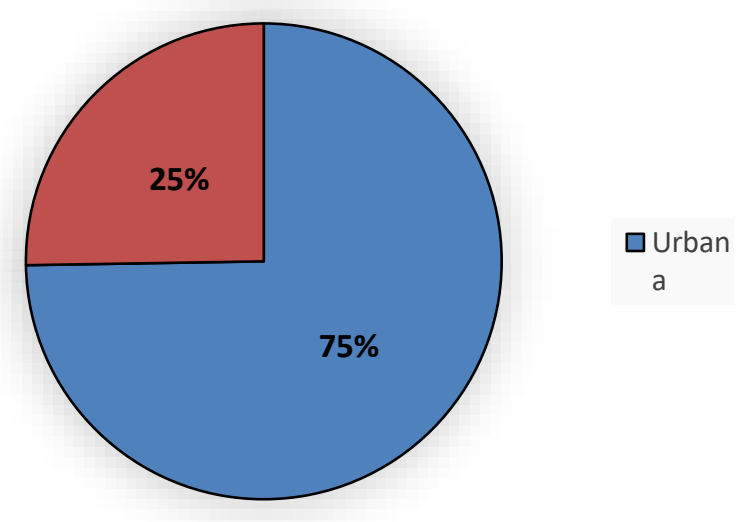

Fonte: DATASUS (2021).

Principalmente entre os alunos da educação infantil e do começo do ensino fundamental, a distância entre a residência e a escola pode ser um fator determinante para a ausência do aluno das salas de aula. Esses problemas são muito recorrentes nas zonas rurais, onde a oferta de escolas pública é ainda menor do que em zonas periféricas da cidade (Abdelkarem, 2019).

É preciso ressaltar também que a situação econômica da família influencia muito nesse fator. Tendo que trabalhar o dia todo para conseguir manter as contas de casa em dia, os pais acabam priorizando o próprio emprego em vez de levar os filhos para uma escola distante. Quando crescem, as crianças logo começam a acompanhar o pai ou a mãe no trabalho (Abdelkarem, 2019).

\section{Conclusão}

O presente estudo teve como proposta avaliar o analfabetismo no Estado do Rio Grande do Norte, esse estudo apresenta em sua discussão os principais fatores para o abandono da população à educação. De forma contínua o Estado sempre tenta alcançar a absoluta erradicação do analfabetismo no Brasil, com iniciativas governamentais como planos, programas campanhas. No decorrer do artigo elaborado, podemos ver que um dos fatores que mais causam o analfabetismo no RN é a desigualdade social e econômica, a má distribuição dos recursos financeiros para as Regiões do país. Isso faz com que as pessoas não tenham acesso a educação local, ou tenham que abandonar seus estudos para poderem trabalhar e assim sobreviver. A partir dos dados e fatos aqui explanados é fundamental que sejam criadas novas estratégias e programas que visem acompanhar a educação no Estado do Rio Grande do Norte, em pleno século XXI um país tão rico quanto o Brasil, já deveria ter abolido o analfabetismo. 
Research, Society and Development, v. 10, n. 3, e56010313877, 2021

(CC BY 4.0) | ISSN 2525-3409 | DOI: http://dx.doi.org/10.33448/rsd-v10i3.13877

\section{Referências}

Abdelkarem, K. N. B. I. (2019). Na caminhada para educar jovens e adultos perpassei pela alfabetização e pelo letramento. Brazilian Journal of Development, 5(5), 3457-3469.

Barbalho, T. (2019). Percentagem de analfabetismo e direito a educação em adultos de 25 a 50 anos do bairro dos coelhos, recife, pe-brasil-ano 2.018. Repositorio de Tesis y Trabajos Finales UAA.

Boas, G. B. V., de Holanda, M. J. B., \& Castro, A. C. (2019). Tendências e perspectivas para erradicação do analfabetismo na EJA. Projeção e Docência, 10(1), 142-153.

Braga, A. C., \& Mazzeu, F. J. C. (2017). O analfabetismo no Brasil: lições da história. Revista on line de Política e Gestão Educacional, 24-46.

Flick, U. (2009). Qualidade na pesquisa qualitativa: coleção pesquisa qualitativa. Bookman Editora.

Fonseca, P. R., \& Negri, O. P. (2019). A formação da Educação de Jovens e Adultos no Brasil.

IBGE-Instituto Brasileiro de Geografia e Estatística. (2015). Síntese de indicadores sociais: uma análise das condições de vida da população brasileira: 2015/ IBGE, Coordenaçãode População e Indicadores Sociais. -Rio de Janeiro: IBGE.

Krasilchik, M. (2008) Prática de ensino de biologia. (4a ed.), Editora Edusp.

Lima Winchuar, M. J., \& Aguera, C. M. (2018). A alfabetização de jovens e adultos na região central do Paraná. EJA em Debate, 7(11).

Medeiros Pereira, A. (2018). A educação nos sertões do Rio Grande do Norte. Mneme-Revista de Humanidades, 19(42), 117-149.

Nicola, J. A., \& Paniz, C. M. (2017). A importância da utilização de diferentes recursos didáticos no Ensino de Ciências e Biologia. InFor, 2(1), 355-381.

Oliveira Pinto, L. (2018). Formação de educadores populares a partir de parceria entre universidade e movimento popular. Interfaces da educação, 9(26), 246269.

Oliveira, M. M. (2016). Como fazer pesquisa qualitativa. (7a ed.), Vozes

Prodanov, C. C. \& Freitas, C. E. (2013). Metodologia do Trabalho Científico: Métodos e Técnicas da Pesquisa e do Trabalho Acadêmico. Novo HamburgoRioGrandedo Sul-Brasil. Associação Pró-Ensino Superior em Novo Hamburgo - Universidade Feevale.

Santos, O. K. C.; \& Belmino, J. F. B. Recursos didáticos: uma melhoria na qualidade da aprendizagem. In: Fórum internacional de pedagogia, 5, Vitória da Conquista, 2013. Anais do V FIPED.

Scarpa, D. L., \& Campos, N. F. (2018). Potencialidades do ensino de Biologia por Investigação. Estudos avançados, 32(94), 25-41.

Silva, M. A. S. et al. Utilização de Recursos Didáticos no processo de ensino e aprendizagem de Ciências Naturais em turmas de $8^{\circ}$ e $9^{\circ}$ anos de uma Escola Pública de Teresina no Piauí. In: Congresso norte nordeste de pesquisa e inovação, 7, Palmas, 2012 Anais do VII CONNEPI.

Soares, M. A. P., \& Ferro, M. D. A. B. (2019). "Contra o terrível mal do analfabetismo": Escopo e raio de ação do jornal "A Escola" (1918-1920). História da Educação, 23.

Souza, S. E., \& de Godoy Dalcolle, G. A. V. (2007). O uso de recursos didáticos no ensino escolar. Arq Mudi. Maringá, PR, 11(2), $110-114$.

Souza, S. M. D. L., Duque, D. C., \& Borim, E. (2017). Propostas pedagógicas para o ensino de Botânica nas aulas de ciências: diminuindo entraves. Revista Electrónica de Enseñanza de las Ciencias, 16(2), 298-315. 